\title{
The Development of E-Commerce in Malaysia
}

\author{
Ainin Sulaiman, Rohana Jani, Shamshul Bahri \\ Faculty of Business and Accountancy, University of Malaya, 50603 Kuala Lumpur
}

\begin{abstract}
E-Commerce has become an important tool in handling different types of business activities emerging from the convergence of several information technologies and business practices. Although E-Commerce has been seen to be an effective and efficient way of doing business, the degree/extend of adoption is still not as extensive and with some reservations amongst both users and non-users. The paper focuses on the analysis of primary data collected via questionnaire on adoption of E-Commerce applications and its constraints. As expected, the results showed that e-mail was the most widely adopted E-Commerce application mainly due to a minimal cost involved in the implementation. The results also revealed that about $27 \%$ of the respondents did not adopt any kind of E-Commerce applications and nearly $75 \%$ of them can be considered as low users (i.e. utilizing less than five applications). Security has been indicated by many to be the top main reason for not adopting E-Commerce.
\end{abstract}

\section{INTRODUCTION}

E-Commerce is now emerging from the convergence of several information technologies and business practices. Among the principal technologies directly enabling modern E-Commerce are computer networking and telecommunications, client/servers computing, multimedia, information retrieval systems and electronic data interchange. E-Commerce is of considerable value whereby it acts as a platform for the formulation of new customer management strategies. This is mainly because E-Commerce directly connects buyers and sellers, support fully digital information exchanges between them and suppress the limit of time and place. In addition, ECommerce support interactivity and therefore can dynamically adapt to customer behavior and can be updated in real time, therefore it is always up to date.

The importance of E-Commerce can be seen from the increase in size of Internet users and growth of electronic commerce worldwide (Strauss and Frost, 1999). In 
Malaysia, a report in The Star IN-TECH April, 18 2000, indicated that in 1995 there were only 7,000 Internet users and in 1999, the size increased by hundred percent (700,000). In addition, The E-Commerce spending in 1997 was RM 12.54 million and this figure is expected to increase to RM 2.46 billion by the year 2002 .

The increase in Internet usage and E-Commerce spending in Malaysia is spearheaded by the Malaysian Government, via the creation of the Multimedia Super Corridor (MSC). The MSC provides low telecommunication tariffs, no censorship on the Internet, plus a well developed IT infrastructure of fibre optic cabling. This complements the rise and growth of the Internet and E-Commerce activities (www.mdc.com.my).

Although E-Commerce is in its early stage of usage in Malaysia, it is expected to change the way organisations carry out their daily transactions. By using ECommerce, organisations will have an added value, whereby it can improve, transform, and redefine their organisations (Bloch et al, 1996).

E-Commerce comprise of a wide range of activities. It is not only exchange of products, services and information electronically (Kalakota and Whinston, 1997) but it also includes new advancement to advertising, market research, customer support service, order and delivery and financial transactions (payment) (Turban et al, 2000).

This study focuses on E-Commerce applications pertaining to these areas. It explores the extent of usage of these E-Commerce applications in Malaysia, namely amongst the Manufacturing, Services and Agriculture/Construction sector.

The paper begins by describing the various ways in which organisations can conduct E-Commerce. It continues with a description of the research methodology, a discussion of the findings, in particular the applications that are most and least widely used. It then proceeds with an analysis of the level of E-Commerce applications by the various organisations. Finally, the paper reveals factors which hinder E-Commerce adoption among the selected organisations.

\section{COMMERCE ON THE INTERNET}

According to The World Trade Organisation (WTO) E-Commerce can be illustrated by reviewing the usage of Internet. The Internet can be used for a mulitude of exchanges and transactions, including e-mails, leisure reading and searching for information (browsing or surfing), advertising and promoting personal or business causes, linking people, selling, purchasing or providing services. It can be concluded that the Internet provides a powerful platform for organisations to conduct E-Commerce.

Advertising includes providing information about the company and its product and services. This can be carried out by displaying the information on the organisation web sites, using a third party website or by means of electronic 
catalogues. A survey of the World Wide Web shows that more and more organisations are putting their catalogues online.

In carrying out market research online organisations can keep in touch with the market environment i.e.: what their competitors is 'up to' and the changing trends of consumers' taste and preferences (Fletcher, 1990). In addition, organisations can also use Internet to monitor their competitors and utilize the Internet for suppliers' evaluation. This would add value to the organisations' procurement decisions as the Internet provides another source of suppliers evaluation (Haynes et al., 1998).

Order and delivery applications include online application/registration, processing sales order and coordinating procurement with suppliers. Some companies provide an online shopping facilities whereby potential customers can shop online. They then uses courier agents to deliver the products. These courier agents on the other hand provides potential customers with services that helps them keep track and trace the movements of their products.

The most important process in any business transactions is making payments or receiving money for the products and services provided. There are companies which allow their customers to pay their online purchases using credit cards. Lately, multimedia technologies have brought about the existence of the smart cards and prepaid cards. Smart cards have been introduced in Malaysia through one of the seven Malaysia Multimedia Super corridor's flagship application (Ainin \& Lee S.L, 1997).

The most common customer support services are the e-mail and FAQ (Frequently Asked Questions) (Kiani, 1998). In addition, customers can lodge complaints or make enquiries by filling online forms. More and more organisations with websites are using these applications extensively.

According to surveys carried out on the use of E-Commerce (Cockburn and Wilson, 1996; Hoffman et al., 1996; Jones and Vijayasarathy, 1998; Haynes et.al, 1998) most organisations use Internet as a vehicle for publicity and advertising, such as providing information about their products. Few companies allow potential customers to order and pay through the Internet.

The results of a survey (Soh et al, 1997) conducted in Singapore illustrated that most of the organisations surveyed used E-Commerce for markerting and advertising, customer support, information gathering and to a lesser degree, electronic transactions such as order and delivery and payment.

Similar study conducted in Greece, indicated that organisations used ECommerce to ensure on-time delivery of their products and services and provide customers information about products. The studied also showed that the less active usage was online payment and placing orders online. 


\section{RESEARCH METHODOLOGY}

\subsection{Sources of Data}

The study utilized both secondary and primary data. The secondary data was based on literature pertaining to the area of interest. Besides hard copy of the literature, soft copy of articles obtained through the Internet was also considered as references. This is to review and understand concepts related to the area of research. Questionnaires were used to collect primary data.

The questionnaire consists of two main sections. The first section comprises of questions on E-Commerce applications and the level/status of adoption of each application, that is, whether or not it is in use, intention to use within the next 2 and 3 years or no intention to use at all. The respondents were asked mainly questions on the type of electronic applications (i.e. Electronic Marketing, Electronic Advertising, Customer Support Service, Order and Delivery and Payment) used by their organization as well as the levels of the usage of each application. This section is designed to capture the trends of the E-Commerce applications adoption among the respondents (organizations).

The second section of the questionnaire required the respondents to rate the level of perceptions regarding factors that hindered them from using more E-Commerce applications. The response was based upon a 5 interval Likert Scale, where 1= 'strongly disagree' and 5 = 'strongly agree'.

The questionnaires were then mailed to the selected organizations. The target respondent was the Chief Executive Officer of the organization or their Information System/Technology (IS/T) Directors or equivalent. A mailing list was then compiled (from the Federation of Malaysian Manufacturer (FMM) Directory, Malaysian Industry Development Authorities (MIDA), and National Productivity Corporation) and the questionnaires were distributed accordingly.

The mailing list (Table 1) consisted of 6468 organizations representing the various sectors of the economy, namely Services (47\%), Manufacturing (46\%) and Agricultural/Construction (7\%).

Table 1 : Distribution of Questionnaires by Sector

\begin{tabular}{|l|c|c|}
\hline \multicolumn{1}{|c|}{ Industry } & No. of Questionnaires & $\begin{array}{c}\text { Percentages } \\
(\boldsymbol{\%})\end{array}$ \\
\hline Manufacturing & 3001 & 46 \\
\hline Agriculture/Construction & 425 & 7 \\
\hline Services & 3042 & 47 \\
\hline Total & $\mathbf{N = 6 4 6 8}$ & $\mathbf{1 0 0}$ \\
\hline
\end{tabular}


A total of 590 responds were received (a response rate of 9\%), out of which, 45.4\% were from the Manufacturing sector, nearly $45 \%$ from Services and $7 \%$ from Construction/Agriculture sector. Although this sample may not be a total representation of the population $(\mathrm{N}=6468)$. the data gathered provide us with useful empirical and important background information on E-Commerce usage in Malaysia, particularly in the selected sectors mentioned above.

\subsection{Methods for Data Analysis}

The data analysis method mainly involved descriptive summary through crosstabulation and frequency distribution of variables of interest. These display provide the overall distribution of the data and highlights any significant features of the variables in the study. A Chi-square test is applied to look at association between factors.

\section{ADOPTION OF E-COMMERCE APPLICATIONS}

\subsection{Types of E-Commerce Applications Used}

Table 2 illustrates the trends of E-Commerce applications adoption in Malaysia. The figures clearly reveal that the top three currently most utilized applications are e-mail (59.7\%) followed by homepage/own business website (33\%) and displaying company information and the product services offered at 32.5\%. Although e-mail was widely used, there were still a fairly large percentage (about 21\%) of the organisations that did not intend to use it at all. This was probably because they did not plan to have Internet access. 
Table 2 Adoption of Applications

\begin{tabular}{|c|c|c|c|c|c|c|c|c|}
\hline \multirow[t]{2}{*}{ Applications } & \multicolumn{2}{|c|}{ In Use } & \multicolumn{2}{|c|}{$\begin{array}{l}\text { Use within } 2 \\
\text { year }\end{array}$} & \multicolumn{2}{|c|}{$\begin{array}{l}\text { Use within } 3 \\
\text { year }\end{array}$} & \multicolumn{2}{|c|}{$\begin{array}{l}\text { Do not Intend to use } \\
\text { at all }\end{array}$} \\
\hline & Freq. & $\%$ & Freq & $\%$ & Freq & $\%$ & Freq & $\%$ \\
\hline Communication e-mai & 352 & 59.7 & 87 & 14.7 & 26 & 4.4 & 125 & 21.2 \\
\hline Home page/ Own Websi & 194 & 32.9 & 193 & 32.7 & 55 & 9.3 & 148 & 25.1 \\
\hline $\begin{array}{l}\text { Displaying company } \\
\text { information and the } \\
\text { product/services offered }\end{array}$ & 192 & 32.5 & 184 & 31.2 & 46 & 7.8 & 168 & 28.5 \\
\hline $\begin{array}{l}\text { Handling customers } \\
\text { feedback/queries on- } \\
\text { line }\end{array}$ & 98 & 16.6 & 200 & 33.9 & 69 & 11.7 & 223 & 37.8 \\
\hline Credit cards & 97 & 16.4 & 97 & 16.4 & 55 & 9.3 & 341 & 57.8 \\
\hline Research on competitors & 92 & 15.6 & 166 & 28.1 & 86 & 14.6 & 246 & 41.7 \\
\hline $\begin{array}{l}\text { On-line application/ } \\
\text { registration }\end{array}$ & 82 & 13.9 & 171 & 29 & 64 & 10.8 & 273 & 46.3 \\
\hline Third party website & 79 & 13.4 & 101 & 17.1 & 40 & 6.8 & 370 & 62.7 \\
\hline $\begin{array}{l}\text { On-line help - product } \\
\text { updates }\end{array}$ & 76 & 12.9 & 207 & 35.1 & 61 & 10.3 & 246 & 41.7 \\
\hline $\begin{array}{l}\text { Processing sales order } \\
\text { from customers on- } \\
\text { line }\end{array}$ & 74 & 12.5 & 197 & 33.4 & 93 & 15.8 & 226 & 38.3 \\
\hline $\begin{array}{l}\text { Research and } \\
\text { evaluation of new } \\
\text { suppliers }\end{array}$ & 73 & 12.4 & 177 & 30 & 84 & 14.2 & 256 & 43.4 \\
\hline $\begin{array}{l}\text { Research on consumer } \\
\text { preference }\end{array}$ & 71 & 12 & 164 & 27 & 82 & 13 & 273 & 46.3 \\
\hline $\begin{array}{l}\text { On-line help- } \\
\text { Frequently asked } \\
\text { question(FAQ) }\end{array}$ & 70 & 11.9 & 193 & 32.7 & 58 & 9.8 & 269 & 45.6 \\
\hline $\begin{array}{l}\text { Tracking incoming } \\
\text { and outgoing good } \\
\text { delivery }\end{array}$ & 53 & 9 & 169 & 28.6 & 91 & 15.4 & 277 & 46.9 \\
\hline Electronic catalogues & 51 & 8.6 & 172 & 29.2 & 70 & 11.9 & 296 & 50.2 \\
\hline $\begin{array}{l}\text { Co-ordinating } \\
\text { procurement with } \\
\text { suppliers on-line } \\
\end{array}$ & 38 & 6.4 & 201 & 34.1 & 99 & 16.8 & 252 & 42.7 \\
\hline Prepaid cards & 24 & 4.1 & 84 & 14.2 & 52 & 8.8 & 430 & 72.9 \\
\hline Smart cards & 22 & 3.7 & 100 & 16.9 & 70 & 11.9 & 398 & 67.5 \\
\hline
\end{tabular}


Among the eighteen E-Commerce applications studied, e-mail was probably the cheapest to implement. In fact the organizations did not have to invest a lot of money to communicate via e-mail as no software or extra hardware were needed. This may be and indications that many organizations were still not ready enough to invest a large sum of money to adopt E-Commerce. Assuming that the organizations were already using computers (equipped with modems), all they needed to do were to register with a service provider to gain access to the Internet for a minimal fee. This implied that it is readily available. In addition, a survey of the World Wide Web showed that there are several companies or search engines that provide free web-based email service. Thus, the expenses incurred will be only for the adoption of the Internet time, whereby charges are based on the local telephone call rates.

On the other hand, applications such as coordinating procurement, monitoring trading and tracking incoming and outgoing goods were not widely used. This is so since these applications require a substantial amount of investment, thus only a few can actually afford to implement them within their organizations. This further substantiated the reason why e-mail is most widely used.

Looking at the mode of payments, $16.4 \%$ of the organisations were currently using credit cards for payments while $57.8 \%$ showed no interest of doing so. This implied that the organisations were concerned about the authentication of the payment system The number of organisations using smart cards and prepaid cards were also very low (less than 5\% each) and the increase in adoption within the next three years was expected to be minimal. Furthermore, the number of organisations that did not intend to use either smart cards or prepaid cards was very high (more than 55\%). This once again indicated that majority of the organisations were not ready to use these mode of payment as the technology is still new and there are not many success stories on its adoption. Nevertheless, with the implementation of the smart card flagship application by the government within the next few years the adoption of smart card is expected to increase.

These findings support the studies conducted by Bloch et. al.( 1996), Cockburn and Wilson, (1996), Soh et al (1997) and Kardaras and Papathanassiou (2000). In addition, we would expect similar findings, if similar research is to be conducted in any country which is just embarking on E-Commerce such as Malaysia's neighboring countries like Thailand, Indonesia and Brunei.

\subsection{Level of E-Commerce Adoption}

Table 3 presents the distribution of total number of E-Commerce applications adoption by the organizations. The number of adoption range between "no usage" to "a maximum of 15" applications used. A total of 18 applications was listed and none of the organizations used all the 18 applications studied. From this table we can observe that nearly $27 \%$ of the respondents did not use any kind E-Commerce applications whereas only $1.5 \%$ used more than 10 E-Commerce applications. 
About $39.5 \%$ used between 1 to 3 types of applications. Next we look at the degree of adoption. Data was grouped into low and high adoption based on the overall percentage distribution. Low user refers to range of adoption between 0 to 4 applications whereas high user is from 5 to 15 applications. It can be then concluded that the level of adoption is very low with nearly $75 \%$ of the respondents were low users and $25 \%$ as high users. These figures reflect that Malaysian organisation is still slow in adopting E-Commerce.

Table 3: Total Number of E-Commerce Applications Adopted by Organisations

\begin{tabular}{|l|l|l|}
\hline Total & Frequency & Percentage (\%) \\
\hline 0 & 158 & 26.8 \\
\hline 1 & 89 & 15.1 \\
\hline 2 & 68 & 11.5 \\
\hline 3 & 76 & 12.9 \\
\hline 4 & 54 & 9.2 \\
\hline 5 & 33 & 5.6 \\
\hline 6 & 35 & 5.9 \\
\hline 7 & 21 & 3.6 \\
\hline 8 & 15 & 2.5 \\
\hline 9 & 17 & 2.9 \\
\hline 10 & 11 & 1.9 \\
\hline 11 & 4 & .7 \\
\hline 12 & 3 & .5 \\
\hline 13 & 3 & .5 \\
\hline 15 & 3 & .5 \\
\hline Total & 590 & 100.0 \\
\hline
\end{tabular}

Detailed analysis by sectors (manufacturing, construction/agriculture and services) and number of applications used shows a significant relationship between the two variables, as reflected in Table 4. This implies that rate of E-Commerce adoption to some extend depends on the type of organizations or business involved. This is clearly reflected by the percentage distribution shown in Table 4. However, it was found that there is no significant relationship between size of organization (small medium versus large) and rate of adoption (Table 5). Small medium organizations in this case refer to those with less than 150 employees while large organizations are those with more than 150 employees. 
Table 4: Distribution of Adoption by Sectors

\begin{tabular}{|c|c|c|c|c|c|c|c|c|}
\hline & \multicolumn{6}{|c|}{ SECTORS } & & \\
\hline \multirow[t]{2}{*}{ Adoptions } & \multicolumn{2}{|c|}{ Manufacturing } & \multicolumn{2}{|c|}{$\begin{array}{l}\text { Construction } \\
\text { /Agriculture }\end{array}$} & \multicolumn{2}{|c|}{ Services } & \multicolumn{2}{|c|}{ Total } \\
\hline & Freq & $\%$ & Freq & $\%$ & Freq & $\%$ & Freq & $\%$ \\
\hline Low users & 213 & 47.9 & 48 & 10.8 & 184 & 41.3 & 445 & 100 \\
\hline High users & 55 & 37.9 & 11 & 7.6 & 79 & 54.5 & 145 & 100 \\
\hline Total & 268 & 45.4 & 59 & 10 & 263 & 44.6 & 590 & 100 \\
\hline $\begin{array}{c}\text { Chi- } \\
\text { square test }\end{array}$ & $\begin{array}{l}\chi^{2}= \\
\text { users }\end{array}$ & $\begin{array}{l}\text {-valu } \\
5 \text { appl }\end{array}$ & $\begin{array}{l}=0.0 \\
\text { ation }\end{array}$ & & & & & high \\
\hline
\end{tabular}

Table 5: Distribution of Adoption by Size of Organisations

\begin{tabular}{|c|c|c|c|c|c|c|}
\hline \multirow{3}{*}{ Adoptions } & \multicolumn{6}{|c|}{ SIZE } \\
\hline & \multicolumn{2}{|c|}{ Small/Medium } & \multicolumn{2}{|c|}{ Large } & \multicolumn{2}{|c|}{ Total } \\
\hline & Freq & $\%$ & Freq & $\%$ & Freq & $\%$ \\
\hline Low users & 239 & 53.7 & 206 & 46.3 & 445 & 100 \\
\hline High users & 70 & 48.3 & 75 & 51.7 & 145 & 100 \\
\hline Total & 309 & 52.4 & 281 & 47.6 & 590 & 100 \\
\hline Chi-square test & \multicolumn{6}{|c|}{$\begin{array}{l}\chi^{2} 1.294(\mathrm{p} \text {-value }=0.255) ; \\
\text { small }<150 \text { employees } ; \text { large }>150 \text { employees } \\
\text { low users }=0-4 \text { applications }: \text { high users }=5-15 \\
\text { applications }\end{array}$} \\
\hline
\end{tabular}

Table 5 reveals that $51.7 \%$ of large organizations are high users of E-Commerce applications while $48.3 \%$ of the small medium organizations are high users. This finding is consistent with earlier findings in an Indian E-Commerce survey (Rao, 2000). 


\section{FACTORS HINDERING ADOPTION}

Besides studying the trends of E-Commerce applications in Malaysia, it is useful and interesting to explore why these organizations are not fully utilizing the applications. It was found that the top four reasons given by the respondents were as follows:

- Insufficient security to prevent hacking and viruses (27.8\%)

- Sales and marketing requires high human interaction (25.8\%)

- Insufficient security for on-line credit payment transaction (23.7\%)

- Cost of setting up of E-Commerce is high (23.6\%)

The findings indicated that security issues seemed to be the main barrier to the implementation of E-Commerce. The organizations were reluctant to use ECommerce as they felt that the transactions conducted electronically were open to hackers and viruses, which are beyond their control. They were also skeptical about the security measures that were implemented to safeguard on-line payment transactions.

These are similar to the findings of the research conducted on the Small Medium Enterprises (SME) in Australia (Lawrence et.al, 1998), the survey conducted by United Kingdom based Industrial Research Bureau (Computimes, Feb. 2000) and Indian E-Commerce survey (Rao, 2000) whereby all the studies illustrated that electronic security is the single major barrier to E-Commerce.

Besides security, the study indicated that financial concerns were also a barrier to E-Commerce implementation. The organizations perceived that the cost of setting up E-Commerce infrastructure is high, therefore they do not intend to use ECommerce applications in their organizations. Although this was indicated by $24 \%$ of the organizations, review of the literature had indicated that application such as Email is very cheap to use. Creation of website also does not incur much cost (cost varies according to design) if designed and maintained by vendors. Electronic advertising using banner on a third party website costs as little as RM400. Hence, we can conclude here that the reason given by the organizations was what they perceived and not based on actual know-how.

\section{CONCLUSION AND IMPLICATIONS}

This study is part of a larger study carried out by the authors in collaboration with the Malaysian National Productivity Corporation. The study was aimed at identifying the level of E-Commerce adoption among Malaysian business organisations. Although more than 6000 questionnaires were distributed, less than ten percent responded.

A total of eighteen applications categorized as electronic marketing, electronic advertising, customer support service, order and delivery and payment were studied. 
The study has indicated that the level of E-Commerce adoption among Malaysian organisations are still relatively low. $26.8 \%$ were not adopting any E-Commerce applications at all while $75 \%$ of the organisations were adopting less than five applications.

The study showed that the most widely used application was communication via the e-mail. It was also found that less than five percent of the organisations actually used the smart card and prepaid card applications. Hence, although Malaysian business organisations do use E-Commerce applications, the adoption was still minimal. This also implied that the use of E-Commerce in Malaysia as a mode of payments, is still lagging. In addition, the results also indicated that Malaysian organisations were still not ready to invest heavily in E-Commerce despite both email and creation of websites are among the cheapest applications to implement and use.

Detailed analysis by sectors (manufacturing, construction/agriculture and services) and number of applications adopted showed a significant relationship between the two variables. This implied that rate of E-Commerce adoption to some extend depends on the type of organizations or business involved. However, it was found that there was no significant association between size of organization (small medium versus large) and rate of adoption

There are various reasons as to why organizations do not use E-Commerce extensively. The findings of this research seem to be similar to those of other studies that aim to elucidate factors that hinder organizations in adopting E-Commerce in either developed or developing countries such as India and Indonesia. Therefore, the cornerstone of Malaysia's move into E-Commerce lies in the transformation of its legal and regulatory environment to support companies undertaking E-commerce. This includes the drafting of the Multimedia Convergence Act, which creates an upto-date communications framework. The Act will be implemented along with the following five high-impact cyber laws: The Digital Signature Cyber Law, The Multimedia Intellectual Property Cyber Law, The computer Crime Cyber law, The Telemedicine Development Cyber law and The Electronic Government Cyber law. Nevertheless the formulation of laws is not sufficient therefore the Government has to play a bigger and more aggressive role in enforcing the laws especially those related to the privacy and security issues if we want to see the increase in ECommerce adoption among Malaysian organizations

Although Malaysia's E-Commerce activities are increasing, the developed countries such as USA and Europe are seen to be in a more advantageous position as they have the latest technology, knowledge and highly skilled and talented human resource. In addition, they are also in a better position in terms of infrastructure, education and suppliers of products and services. Most importantly they have a bigger market share and better access to market. MSC is suppose to be the Malaysian catalyst for E-Commerce infrastructure and human resource development. However, since E-Commerce in Malaysia is still at the infancy stage, it 
is still early to make any conclusive statements as to whether the MSC has successfully encouraged the growth of E-Commerce in Malaysia.

\section{REFERENCES}

Ainin S.and Lee S.L, (1998), Smart cards: Towards Management Excellence, Proceedings of the Association of Asian Management, Malaysia.

Bloch M, Yves and Segev A., The Road of Electronic Commerce - a Business Value Framework. Gaining Competitive Advantage and Some Research Issues,” March 1996.

Clarke R. (1993), The Strategic Intent of On-Line Trading Systems : A Case Study in National Livestock Marketing, Xamax Consultancy Pty Ltd.

Clarke. R (1993), EDI Is But One Element of Electronic Commerce, Xamax Consultancy Ptd Ltd.

Cook, David and Sellers. D (1995), Launching a business on the Web, Que Corporation.

Cockburn C and Wilson T (1996), Business use of the WWW, International Journal of Information Management, vol 16:2.

Fletcher (1990), Marketing Management and Information Technology, Prentice Hall.

Foo, Fran (1998), "Becoming a role model for e-commerce," The Star: In-Tech, September 22 1998, pp. 33-34.

Gummesson. E (1997), “Relationship Marketing (RM) and the Imaginary Organization Proceedings of the European Marketing Academy Conference, " ESSEC, Paris. In Miers, Derek and Hutton, Graham (1988), "The Strategic Challenges of Electronic Commerce," England.

Haynes. P, Becherer. R, Helms. M (1998), “ Small and mid-sized businesses and Internet use: unrealised potential?," Internet Research: Electronic Networking Application and Policy, Volume 8, number 3, pp. 229-235.

Hoffman. D, Novak. T, Chatterje. P (1996), Commercial Scenarios for the Web: Opportunities and Challenges", Project 2000: Research Program on Marketing in Computer-Mediated Environments, Own Graduate School of management, Vanderbilt University.

Kalakota. R, Whinston. A (1997), Electronic Commerce : A Manager's Guide, Addison Wesley.

Kardaras D and Papathanassiou E., (2000), The development of B2C e-commerce in Greece, Internet Research, vol 10:4, pp 1066-2243.

Kosiur. D (1997), Understanding Electronic Commerce, Microsoft Press.

Kiani, Riza. G (1998), “ Marketing Opportunities in the digital world," Internet research: Electronic Networking Applications and policy, Volume 8, number 2, pp. 185-194.

Lawrence. E, Corbitt. B, Tidwell. A, Fisher. J, Lawrence. J (1998), Internet Commerce : Digital Models For Business, John Wiley \& Sons Australia, Ltd.

Rao S., (2000), E-Commerce: The medium is the mart, New Library World, vol 101: 11542000, pp53-59.

Soh. C, Quee.M, Fong. G, Chew. D, Reid. E (1997), “ The use of the Internet for business: the experience of early adopters in Singapore," Internet Research: Electronic Network Application and Policy, Volume 7, number 3, pp. 217-228.

Straus J. and Frost R. (1999), Marketing on the Internet, Prentice Hall, Upper Saddle River, NJ. 
Timmers P.( 1999), Electronic Commerce:Strategies and Models for Business to Business Trading, John Wiley \& Sons, Chichester.

Tull D and Hawkins D., (1987), Markerting Research, Macmillian Publishing Company, New York,

Turban E., Lee J., King D., Chung H.M (2000), Electronic Commerce: A Managerial Perspective $\left(1^{\text {st }}\right.$. Edition), Prentice-Hall, Inc.,

Zwass V .(1998), "Structure and Macro-Level Impacts of Electronic Commerce : From

Technological Infrastructure to Electronic Market Places" in Emerging Information Technologies ed. Kenneth E. Kendall, Thousand Oaks, CA: Saga Publications. 